tions were necessarily taken in drilling subsequent wells on this site, with the result that a prolific production was obtained. In fact, so prolific is the production that to fulfil an annual contract of 4 million tons, only fifteen of the thirty wells drilled need be tapped. Moreover, as Kirkuk is the only one of the ten selected sites which has been developed, the future supply of Iraq oil is potentially enormous.

The pipe-lines which run from the oilfield to the Mediterranean sea are among the most remarkable of their kind. There are longer lines in the United States, but none required greater engineering skill and endurance. Practically the whole line is laid through barren inaccessible territory and the workers are obliged to make roads, huts and means of communication before they can begin on actual construction. Moreover, they have frequently suffered from shortage of drinking water and have had little or no protection against extremes of heat and cold.

The proposed pipe-line course was modified several times in the early stages of the project, but the final form is that of the letter Y. The pipes run in a double track from Kirkuk, across the Tigris to the Euphrates where they fork, one line northward and the other southward. The former is the shorter and easier route and terminates at El Mina, near Tripolis. The southern line, which has proved much more difficult to lay, is not yet completed, but will eventually be carried to the Bay of Acre near Haifa. Two thousand kilometres of steel tubes, representing a weight of 116,000 tons, have been laid at depths varying from one to several metres, through the most difficult territory in the world, in order to accomplish this engineering feat. Moreover, 500 Europeans and Americans and 6,000 natives have been employed in the construction. The cost of laying the lines is naturally considerable, having regard to the peculiar difficulties which had to be overcome, and the question arises as to whether the construction is, and will be, in the future, economically worth while.

In the first instance, Tripolis and Haifa are geographically better situated for the exportation of petroleum than the ports of Russia and Roumania, or even of the New World, for they are considerably nearer the chief centres of importation. Cost of transport will therefore be low in comparison with that paid by rival countries. Cost of production is likewise low owing to the large quantity of oil procurable from each well, the vast dimensions of the oilfields, and the ease with which drilling operations are effected. It is therefore conceivable that the oil of Iraq will in the future be the cheapest and most accessible in the world, although it originates in, and has to flow through, such apparently impossible territory.

\title{
Obituary
}

\section{Harriet Brooks (Mrs. Frank Pitcher)}

$\mathrm{H}$ ARRIET BROOKS (Mrs. Frank Pitcher), who died in Montreal on April 17, was wellknown in the years 1901-5 for her original contributions to the then youthful science of radioactivity. A distinguished graduate of McGill University, she was one of the first research workers with Prof. (now Lord) Rutherford in Montreal. She observed that the decay of the active deposit of radium and actinium depended in a marked way on the time of exposure to the respective emanations and determined the curve of decay for very short exposures. This work, which was done before the transformation theory of radioactive substances was put forward, assisted in unravelling the complex transformations which occur in these deposits. With Rutherford she determined the rate of diffusion of the radium emanation into air and other gases. These experiments were at the time of much significance, for they showed that the radium emanation diffused like a gas of heavy molecular weight-estimated to be at least 100 .

Miss Brooks entered the Cavendish Laboratory, (ambridge, in 1903 and continued her radioactive investigations. In a letter to NATURE of July 21, 1904 (vol. 70, p. 270) she directed attention to a peculiar type of volatility shown by the active deposit of radium immediately after its removal from the emanation. In the light of later results of Hahn and Russ and Makower in 1909, it is clear that the effect was due to the recoil of radium $B$ from the active surface accompanying the expulsion of an $\alpha$-particle from radium $A$. This method of separation of elements by recoil ultimately proved of much importance in disentangling the complicated series of changes occurring in the radioactive bodies.

After her marriage to Mr. Frank Pitcher of Montreal, she gave up her research work but took a strong interest in university affairs. In this she was aided by her family ties, for one sister is the wife of Sir Charles Gordon, a prominent supporter of McGill University, and another the wife of Prof. A. S. Eve, professor of physics in MeGill University. A woman of much charm and ability, she was a welcome addition to any research laboratory and left in all who met her a vivid impression of a fine personality and character. $\mathbf{R}$.

\section{Dr. H. Basenow}

THE recent death of Dr. Herbert Basedow at the age of fifty-two years, which is announced in a dispatch by Reuter from Adelaide, will be deeply regretted by anthropologists in Great Britain, where his persistent and courageous efforts on behalf of the Australian aborigines, which brought about the allotment of an extensive 